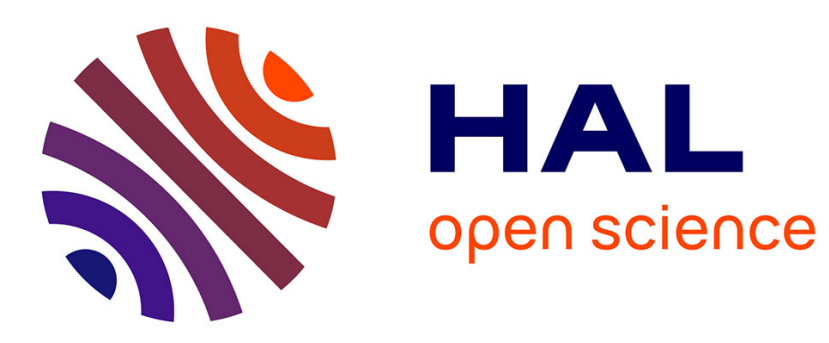

\title{
Opacity in Campidanian Sardinian metaphony
}

Francesc Torres-Tamarit, Kathrin Linke, Maria del Mar Vanrell

\section{To cite this version:}

Francesc Torres-Tamarit, Kathrin Linke, Maria del Mar Vanrell. Opacity in Campidanian Sardinian metaphony. Natural Language and Linguistic Theory, 2017, 35 (2), pp.549-576. 10.1007/s11049-0169341-0 . hal-01677695

\section{HAL Id: hal-01677695 \\ https://hal.science/hal-01677695}

Submitted on 8 Jan 2018

HAL is a multi-disciplinary open access archive for the deposit and dissemination of scientific research documents, whether they are published or not. The documents may come from teaching and research institutions in France or abroad, or from public or private research centers.
L'archive ouverte pluridisciplinaire HAL, est destinée au dépôt et à la diffusion de documents scientifiques de niveau recherche, publiés ou non, émanant des établissements d'enseignement et de recherche français ou étrangers, des laboratoires publics ou privés. 


\title{
Opacity in Campidanian Sardinian metaphony
}

\author{
Francesc Torres-Tamarit • Kathrin Linke • \\ Maria del Mar Vanrell
}

Received: date / Accepted: date

\begin{abstract}
This paper develops an analysis of two opaque interactions in Campidanian Sardinian that involve metaphony and two other processes, vowel merger in the suffixal domain and word-final vowel epenthesis. The analysis is developed within the formalism of Turbidity Theory, a model assuming containment, combined with privative features, maximal economy in the representation of segments and relativized scope. The basic idea is that metaphony is computed synchronically as a non-local licensing condition of a feature $\{$ high $\}$ only if it is underlyingly present. We discuss, on the one hand, cases of non-application of metaphony induced by a subset of high vowel inflectional suffixes. We show that underapplication of metaphony in Campidanian Sardinian is due to insertion of a feature $\{$ high $\}$ in this set of non-low suffixes lacking \{high\} underlyingly, which does not need to be licensed as it is not lexical. On the other hand, metaphony also underapplies in the presence of epenthesized high vowels, because their feature $\{$ high $\}$ is again inserted since these vowels have no correspondent in the input. This paper presents an account that allows the implementation of the interacting processes such as metaphony, vowel merger and word-final vowel epenthesis into one paral-
\end{abstract}

F. Torres-Tamarit

Structures Formelles du Langage (UMR 7023)

CNRS/Paris 8

59/61, rue Pouchet

75017 Paris, France

E-mail: francescjosep.torres@gmail.com

K. Linke

Institut für Germanistik

Universität Wien

Universitätsring 1

1010 Wien, Austria

E-mail: kathrin.linke@univie.ac.at

M. Vanrell

Institut für Romanische Philologie

Freie Universität Berlin

Habelschwerdter Allee 45

14195 Berlin, Germany

E-mail: mariadelmar.vanrell@fu-berlin.de 
lel OT computation. With the help of work on inventory structure, the opaquely interacting processes can be modelled without relying on rule ordering.

Keywords Campidanian Sardinian · Feature privativity · Vowel epenthesis . Metaphony · Opacity · Turbidity Theory · Vowel merger

\section{Introduction and data}

Romance metaphony is a type of long-distance assimilatory process in which an unstressed high vowel inflectional suffix causes raising of a preceding stressed (mid)

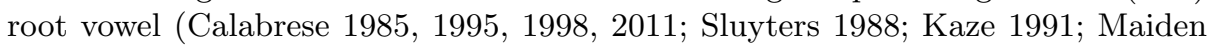
11991; Dyck 199.5; Cole 19.98; Nibert 1998; Walker 20105; Grimaldi 2010.9; Mascaró 2011).

In many Italian dialects with an underlying seven-vowel inventory, metaphony raises high-mid vowels /e, o/ to high [i, u], whereas low-mid vowels / $\varepsilon$, o/ are affected non-uniformly depending on the system; low-mid vowels either diphthongize (variety of Calvello, Gioscio 1985; Calabrese 2011), raise to high-mid (variety of Servigliano, see $\boldsymbol{\nabla})$, raise all the way up to high (variety of Foggiano, see $\mathbf{\square}$ ), or stay unaffected (variety of Grado, Ascoli 18.98; Maiden 1991; Walker 200.5).

As a matter of illustration, consider Foggiano. In this northern Pugliese variety, both low-mid and high-mid vowels undergo metaphony and raise to high when preceding a high vowel inflectional suffix (see $\mathbf{\square}$ ).

(1) Foggiano (Calabrese 11998, 2011)

\begin{tabular}{|c|c|c|c|}
\hline 'kjen-a] & 'full-FEM.SG' & 'kjin-u] & 'full-MASC.SG' \\
\hline 8$]$ & 'soft-FEM.sG' & $\left.\mathrm{mu} \iint-\mathrm{u}\right]$ & 'soft-MASC.SG' \\
\hline t-e] & 'foot' & pit-i] & 'feet' \\
\hline gross-a] & 'big-FEM.SG' & 'gruss-u] & 'big-MASC.SG' \\
\hline
\end{tabular}

Metaphonic raising can also be step-wise; low-mid vowels raise to high-mid, and high-mid vowels to high. Servigliano, a dialect of Marchigiano (Marche), exemplifies this case of synchronic chain shift (『)

(2) Servigliano (Camilli ए.929; Mascaró 2011)

$\begin{array}{llll}\text { ['pes-a] } & \text { 'heavy-FEM.SG' } & \text { ['pis-u] } & \text { 'heavy-MASC.SG' } \\ \text { ['fjor-e] } & \text { 'flower' } & \text { ['fjur-i] } & \text { 'flowers' } \\ \text { ['ped-e] } & \text { 'foot' } & \text { ['ped-i] } & \text { 'feet' } \\ \text { ['mort-a] } & \text { 'dead-FEM.sG' } & \text { ['mort-u] } & \text { 'dead-MASC.SG' }\end{array}$

The case of metaphony in Campidanian Sardinian (henceforth CS, southern Sardinia) is particularly interesting. First, CS has a surface seven-vowel system in stressed position (3). Some examples appear in (国).

(3) CS surface seven-vowel system in stressed position

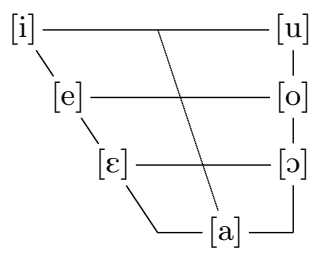


(4) CS stressed vowels (Bolognesi 1998; Frigeni 20102)

$\begin{array}{ll}\text { [es'siri] } & \text { 'to go out' } \\ {\left[J^{\prime} \beta \text { ettu] }\right.} & \text { 'open-MASC.SG' } \\ \text { ['Erba] } & \text { 'grass' } \\ \text { ['akkua] } & \text { 'water' } \\ \text { ['ora] } & \text { 'hour' } \\ \text { ['orku] } & \text { 'ogre' } \\ \text { ['uttimu] } & \text { 'last-MASC.SG' }\end{array}$

The distribution of stressed mid vowels, however, is predictable. Stressed highmid vowels are restricted to appear before unstressed high vowels. In fact, low-mid vowels productively alternate with high-mid vowels, the latter always followed by a high vowel inflectional suffix. Metaphony in CS thus raises low-mid vowels to high-mid (国).

(5) CS metaphony (Bolognesi 19998; Frigeni 2002)

$\begin{array}{llll}\text { [ni'edd-a] } & \text { 'black-FEM.sG' } & \text { [ni'edd-u] } & \text { 'black-MASC.SG' } \\ \text { ['ver-a] } & \text { 'true-FEM.sG' } & \text { ['ver-u] } & \text { 'true-MASC.SG' } \\ \text { ['no-a] } & \text { 'new-FEM.SG' } & \text { ['no-u] } & \text { 'new-MASC.SG' } \\ \text { ['mott-a] } & \text { 'dead-FEM.SG' } & \text { ['mott-u] } & \text { 'dead-MASC.SG' }\end{array}$

Following Bolognesi (11998) and Frigeni (2002), we assume that high-mid vowels are allophones of low-mid vowels (whereby high-mid vowels derive from low-mid vowels) and that the contrastive vowel system of CS contains only five vowels (6). The outcome of metaphony in CS, that is, high-mid vowels, are therefore not phonemic segments in the system; it is worth noting that CS is unique in this respect ( $c f$. Servigliano, where high-mid vowels are contrastive segments). Any phonological analysis of metaphony in CS must therefore exclude high-mid vowels in contrasting positions, like in the stressed position of a root, unless they are followed by a metaphonizing high vowel suffix. The examples in ([) further suggest that low-mid vowels are phonemic rather than high-mid vowels, because if high-mid vowels were phonemic, there would be no reason to ever get low-mid vowels before high vowel suffixes.

(6) CS contrastive five-vowel system in stressed position

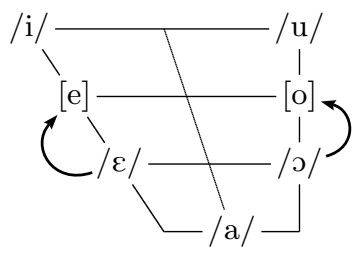

Interestingly, metaphony in CS underapplies in two situations. Firstly, low-mid vowels can also be found before high vowel inflectional suffixes (right column in च). This is a case of non-surface-true opacity, in which metaphony does not apply although the surface conditions are met.

\footnotetext{
1 One argument in favor of considering metaphony a productive synchronic process is that speakers of CS consistently apply the process of metaphony in Standard Italian with no exceptions (Caroline Bacciu p.c.). Standard Italian, however, has no metaphony.
} 
(7) Underapplication of metaphony (Bolognesi ए998)

$\begin{array}{llll}\text { ['son-u] } & \text { 'sound' } & \text { ['son-u] } & \text { 'I play' } \\ \text { ['oy-u] } & \text { 'eye' } & \text { ['oy-us] } & \text { 'eyes' } \\ \text { ['ben-i] } & \text { 'come-IMP' } & \text { ['ben-i] } & \text { 'good/well' } \\ \text { ['Jet-i] } & \text { 'only' } & \text { ['fet-i] } & \text { 'flour' }\end{array}$

In the suffixal domain, CS shows a reduced surface three-vowel system; mid vowels never surface. However, diachronic and inter-dialectal evidence exists indicating that the suffixes which do not cause metaphony can be treated as derived high vowels, that is, phonemic mid vowels that merged on the surface with high vowel suffixes (see Bolognesi [998; Frigeni] 20102). Since the contrast between high and mid is lost in this position, the structural context that inhibits metaphony is now opaque in the synchronic grammar of CS. In other words, vowel merger towards high vowels hid the triggering environment for metaphony (《).

(8) CS surface three-vowel system in the suffixal domain

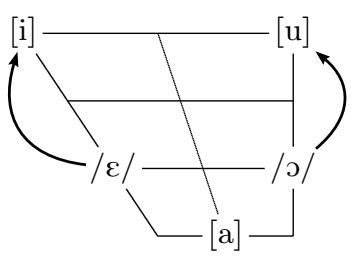

This specific case of non-application of metaphony in CS is connected with a long-standing debate on the representation of vowels that behave exceptionally in vowel harmony and the issue of abstractness in phonology. An influential early contribution on exceptionally behaving vowels in harmonic systems was Vago (11973). Vago (11973) noted that deviant patterns of vowel harmony could be understood if different vocalic underlying feature specification were postulated. As in $\mathrm{CS}$, these effects often resulted from diachronic mergers in the system. What Vago (IIT3) proposed was the incorporation of abstract segments alongside absolute neutralization rules. These positions led to ongoing debates about abstractness in phonology. More recently, the issue of exceptional vowels in harmony systems and the need for abstract levels of analysis have been challenged, for instance, in Benus and Gafos (20107). Benus and Gafos (20107) have shown that front vowels in Hungarian that do not participate in selecting front suffixes are less advanced (i.e. they show a more retracted tongue body) than their counterparts that do select front suffixes even in bare stem forms with no suffixes. In this paper, we do not claim such a thing for CS. We claim that in CS the underlying representation of metaphonizing versus non-metaphonizing suffixes are phonologically different and that the differing underlying representations get neutralized on the surface due to positional markedness.

The second case of underapplication of metaphony in CS can be found when metaphony interacts with a process of word-final vowel epenthesis. Word-final vowel epenthesis applies in two different environments. First, it applies after stressed

\footnotetext{
2 We prefer not to use the term vowel reduction because of the absence of morphophonological alternations; all suffixes are always unstressed. Instead, we call this process vowel merger, although we do not imply that it is diachronic. In fact, we will analyze it as synchronic vowel neutralization.
} 
vowels in word-final position as a way to prevent final stress, which is always prohibited in CS (四).

(9) Vowel epenthesis after word-final stressed vowels (Bolognesi [998)

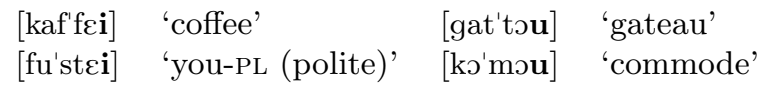

Vowel epenthesis also applies after word-final consonants. ${ }^{[}$As can be seen in (미), the epenthetic vowel, in boldface, surfaces as a high front vowel if the root has a stressed mid front vowel, and as a high back vowel if the root has a stressed back vowel. Note that epenthetic vowels, which are always high, do not trigger metaphony.

(10) Vowel epenthesis after word-final consonants after stressed mid vowels

$$
\begin{array}{lll}
{[\text { 'sczi }]} & \text { 'you are' } & *[\text { 'sezi }] \\
{[\text { 'nэzu }]} & \text { 'we' } & *[\text { 'nozu }]
\end{array}
$$

The backness of the epenthetic vowel also depends on the preceding lexical vowel even if it is unstressed (पI).

(11) Vowel epenthesis after word-final consonants after unstressed vowels

$$
\begin{aligned}
& \text { [kal'mant-i-zi] 'quiet-PL' } \\
& \text { ['roz-a-za] 'rose-PL' } \\
& \text { [mila'nعz-u-zu] 'Milanese-PL' *[mila'nez-u-zu }]
\end{aligned}
$$

Previous literature on CS states that vowel epenthesis applies after word-final codas in pre-pausal positions (Flack 20109), and also at the edge of phonological phrases and prosodic words (Bolognesi 11998). To replicate these findings, we collected data from three locations in southern Sardinia and recorded five speakers: one male from Sìnnia, two females from Biddecrèsia, and one male and one female from Seddori. Sardinian was their dominant language.

We conducted a production experiment based on a translation task from Italian to Sardinian. The materials included a set of DPs that always contained two words, a noun plus an adjective (rose sarde $\rightarrow$ rosas sardas 'Sardinian roses'). The first word always ended in /-s/, which corresponds to the plural morph. The second word began in different consonants, including obstruents and sonorants. Speakers were asked to pronounce the phrases at a normal speech rate and avoid pauses between words. When a break occurred, the item was presented a second time at the end of the session. The translation task did not present any problem of inducement.

As is well-known from previous literature on Sardinian, vowel epenthesis is robust in pre-pausal contexts. The insertion of an epenthetic vowel is triggered to satisfy the markedness constraint No-CODA. This is the only repair strategy found in this prosodic environment. However, in utterance-medial position, two different processes were attested: vowel epenthesis and consonant deletion (ए2).

\footnotetext{
3 Codas in CS comply with the Coda Condition principle: obstruents in coda position are only possible if geminated, and nasals are homorganic with the following consonant. Both /r/ and /s/ may surface in coda position; the latter, however, follows a more intricate pattern (see Bolognesi 14998 for more details).
} 
(12) Vowel epenthesis and consonant deletion within an intonational phrase

\begin{tabular}{|c|c|c|c|c|}
\hline [,rozaza 'zardaza] & $\sim$ & [,roza 'zardaza] & rosas sardas & 'Sardinian roses' \\
\hline [,domuzu 'mannaza] & $\sim$ & [,domu 'mannaza] & domus mannas & 'big houses' \\
\hline [,frorizi 'ledzuzu] & $\sim$ & [,frori 'ledzuzu] & froris lègius & 'ugly flowers' \\
\hline [,rozaza yal'mantizi] & $\sim$ & [,roza yal'mantizi] & rosas calmantis & 'calming roses' \\
\hline
\end{tabular}

We have not found any pattern that could explain under which conditions the two processes are selected."

What is relevant for the analysis presented in this paper is that both vowel merger in the suffixal domain (区) and vowel epenthesis (WU) interact opaquely with metaphony. In a rule-based framework, one would say that vowel neutralization in underlyingly non-high suffixes, on the one hand, and insertion of epenthetic high-vowels in word-final position counter-feed metaphony.

Such an opaque interaction poses a challenge for standard parallel Optimality Theory (OT), in which no reference to intermediate levels of representation is possible. To illustrate this, let us assume for now that metaphony in CS is the result of spreading the feature $\{+\mathrm{ATR}\}$ of a high vowel suffix (as assumed in Calabrese 201I) onto a preceding low-mid stem vowel ([13). We use the informal markedness constraint $\operatorname{SPREAD}(\{+\mathrm{ATR}\})$, which must dominate the faithfulness constraint $\operatorname{IDENT}(\{\mathrm{ATR}\})$ in order to derive metaphony. We exemplify metaphony with an abstract input /o-u/.

(13) Spreading of $\{+$ ATR $\}$

\begin{tabular}{|c|c|c|}
\hline o-u & $\operatorname{SpREAD}(\{+\operatorname{ATR}\})$ & $\operatorname{IDENT}(\{\operatorname{ATR}\})$ \\
\hline 1. $\mathrm{o}-\mathrm{u}$ & & $*$ \\
\hline 2. 'ว-u & $* !$ & \\
\hline
\end{tabular}

What is crucial for the present analysis is that even if non-metaphonizing suffixes are assumed to be underlyingly $\{-\mathrm{ATR},-$ high $\}$, the opaque candidate with neutralization of the suffix and non-application of metaphony has no chance to be selected as the optimal candidate (피). We introduce an informal constraint NEUTRALIZE that prohibits mid vowels in the suffixal domain. This constraint triggers neutralization of the non-metaphonizing suffix and must be ranked above $\operatorname{IDENT}(\{\mathrm{ATR}\})$. However, $\operatorname{SPREAD}(\{+\mathrm{ATR}\})$ still prefers the transparent candidate, candidate (a), although the actual form in CS is the opaque candidate (b) with neutralization but no metaphony.

(14) Failure to select the opaque candidate

\begin{tabular}{|c|c|c|c|}
\hline ว-ว & Neutralize & $\operatorname{SpREAD}(\{+\operatorname{ATR}\})$ & $\operatorname{IDENT}(\{\operatorname{ATR}\})$ \\
\hline 1. $\mathrm{O}-\mathrm{u}$ & i & & $* *$ \\
\hline 2. $:-$ 'ว-u & 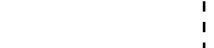 & $* !$ & $*$ \\
\hline 3. 'ว-ว & $* !$ & & \\
\hline
\end{tabular}

4 Some speakers tend to favor consonant deletion over vowel epenthesis. The reverse situation is not found. Such a high degree of variation has never been reported before. Future research is thus necessary to address which factors drive the selection of either vowel epenthesis or consonant deletion to avoid a word-final consonant within an intonational phrase. 
In this paper, we present an analysis of metaphony in CS that makes use of feature privativity, that is, monovalent features, and Turbidity Theory (OT$\mathrm{TT}$ ), a version of OT that allows for a distinct treatment of lexical versus derived features without the need to refer to other levels of representation than the surface representation. First, as opposed to Frigeni (2002) and Calabrese (2011), who assume $\{(+)$ ATR $\}$ to be the feature responsible for metaphony in CS, we will argue that it is the monovalent feature $\{$ high $\}$, as in many other Italo-Romance varieties. We will further allow for relativized scope of monovalent features; in other words, features can cover different sections of the inventory depending on the system. This will allow us to postulate that the step-wise raising in CS is the result of spreading the monovalent feature $\{$ high $\}$ to a mid vowel that contains the feature $\{$ low , thus resulting in a $\{$ high,low vowel, which is nevertheless banned in the language in contexts other than metaphony. This solution hinges on the issue of abstractness in phonology, as will be discussed in more detail in the next section. The fact that some suffixes do not participate in metaphony will receive a straightforward explanation in terms of TT: only a lexical \{high $\}$ feature spreads. If the $\{$ high $\}$ feature is derived, that is, inserted in order to satisfy the neutralizing requirement on suffixes, there will be no need to spread the feature.

The content of the paper is organized as follows. The theoretical framework is developed in $\S 2$. The analysis is presented in $\S 3$. In $\S 4$, we present the results of the factorial typology of the proposed constraint set. We demonstrate that the analysis developed for CS accounts for all basic patterns of metaphony in ItaloRomance. The differences between our analysis and that of Frigeni ( 20102$)$, the most recent formal analysis of the CS vowel system, is discussed in $\S 5$, followed by a discussion in which we discuss alternative accounts based on featural affixation and morpheme-specific constraints. The paper concludes in $\S 6$.

\section{Theory}

\subsection{Representations}

Our representational assumptions rest upon the principles of feature privativity, feature economy, and relativized scope developed in Dyck (109.5) and Frigeni (2002).

We assume that phonological features have no values; they are privative. Furthermore, the number of features that make up a segment is the fewest possible to reflect its phonological activity. A feature is understood to be phonologically active if the presence of that feature either expresses a lexical contrast or a noncontrastive, allophonic alternation.

Phonological features can have scope over different sections of the inventory. Relativized scope presupposes that two different languages may share the same number of segments in their surface inventory but differ in the way these segments are phonologically specified. Dyck ([199.5) argues in favor of an algorithm for determining height distinctions in Italo-Romance vowels. First, the feature $\{$ low introduces a contrast between a low region and a non-low region. Having one feature would produce a two-height-levels inventory (ए5). The gray circle stands 
for specified by the feature \{low \} and capital E, O stand for unspecified non-low vowels, which are not necessarily phonetically mid.

(15) A two-height-levels inventory (Dyck 11995)

$\mathrm{E}$ $\mathrm{O}$

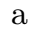

After assigning the feature $\{$ low , if a system additionally requires a contrast in the non-low vowel region, the feature $\{$ high $\}$ is introduced. High vowels are specified by the feature $\{$ high , whereas mid vowels are left unspecified. A threeheight-levels inventory is therefore created (ㅁ). The ellipse stands for specified for $\{$ high $\}$.

(16) A three-height-levels inventory (Dyck 199.5)

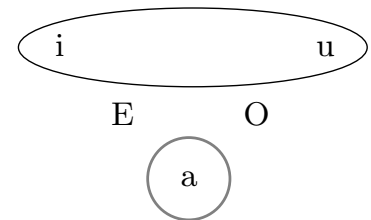

For a four-height-levels inventory in which mid vowels contrast, no extra height feature is necessarily needed - a modification of the configurational scope of $\{$ low $\}$ such that low-mid vowels are also specified for $\{$ low $\}$ yields the desired extra height distinction. High-mid vowels, however, receive no height features. The independent need for place features such as \{front (dashed) and $\{$ back $\}$ (dotted) is enough to distinguish between mid vowels and the low vowel, which never contrasts for place in Romance ([7).

(17) A four-height-levels inventory (Dyck 1995:5)
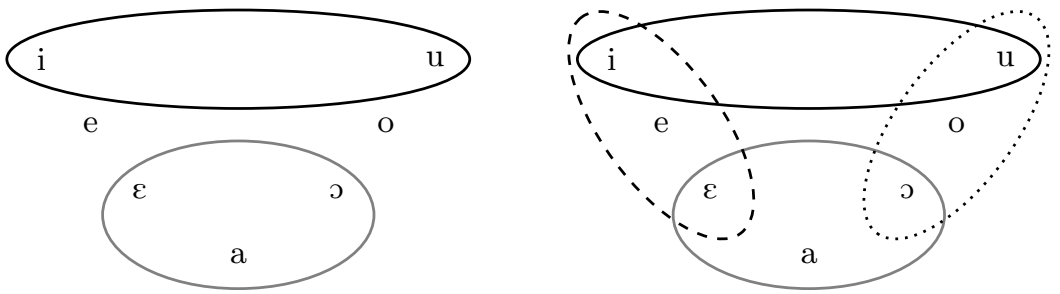

The way phonological features are assigned to vowels in CS represents a more intricate exercise than that proposed in Dyck (11995) for other Italo-Romance varieties. As opposed to Calabrese (2011) and Frigeni (20102), who assume metaphony

5 We assume that unspecified segments are handed over to the phonetics component, which will assign a language-particular interpretation to those segments. With respect to mid vowels, when we represent them with capital letters /E, O/, we express the fact that they are phonologically unspecified for height within the mid vowel region. As pointed out by Calabrese (खणII), in Italo-Romance systems with no phonemic distinction within the mid vowel region, these mid vowels are usually interpreted as low-mid, lax vowels.

6 Alternatively, for other languages with a four-height system, the scope of the feature $\{$ high $\}$ could be extended. 
to be caused by spreading of the feature $\{+\mathrm{ATR}\}$, we consider that metaphony, even in CS, is always the result of spreading the feature $\{$ high $\} .^{\mathbb{0}}$

Based on the differing phonological patterning of the vowels we propose that the four features $\{$ high $\},\{$ low $\}$, front $\}$ and $\{$ back $\}$ are contrastive in their distribution in CS. ${ }^{\square}$ The fact that the two sets of front vowels and back vowels pattern symmetrically to the exclusion of [a] indicates that both place features play an active role in the grammar. Furthermore, a process such as metaphony presents evidence that high vowels form a natural class in CS. Lastly, CS distinguishes three height levels, so a second height feature, e.g. \{low $\}$, is necessary.

We follow Levelt and Van Oostendorp (2007) in assuming that with each acquired feature becoming available to the grammar in the course of acquisition, all possible combinations of these features are generated. For $n$ different features that results in $2^{n}$ different combinations. Some combinations of these features are allowed in the grammar, whereas others are not. Which combinations are allowed and which are not is decided on the basis of positive evidence (phonological contrast and allophonic alternations). For each feature combination, there is a corresponding feature co-occurrence constraint (FCC) that is activated..$^{\mathbf{9}}$

FCCs of the type $*\{F, G\}$, and also ${ }^{*} F$, are violated whenever a (cluster of) feature(s) is pronounced (Levelt and Van Oostendorp 2007; Van Oostendorp 2014) (ㅁ).

(18) Markedness constraints

a. ${ }^{*} F$ : assign a violation mark for every pronunciation of the feature $F$.

b. $*\{F, G\}$ : assign a violation mark for every pronunciation of the features $F$ and $G$ by the same root node.

The language-specific ranking of these FCCs shapes the vowel inventory. With regard to CS, we assume that the $\mathrm{FCCs} *\{$ front,back $\}$ and $*\{$ high,low $\}$ are relatively high-ranked in contrast to e.g. $*\{$ high,front $\}$.

In addition, we claim that a height specification is mandatory for all vowels in $\mathrm{CS}$ and that high vowels require a place specification. Therefore, besides FCCs of the type $*\{F, G\}$, another type of constraint is needed: implicational FCCs (Van Oostendorp 2014) (एप) (top-ranked $\mathrm{V} \Rightarrow\{$ HeIGHT $\}$ and $\{$ high $\} \Rightarrow\{$ PlaCE $\}$, respectively).

(19) Implicational constraint ("if-then-constraint")

$F \Rightarrow G$ : assign a violation mark for every root node that contains a feature $F$ and does not also contain a feature $G$.

Table $\mathbb{U}$ sketches how the phonemic five vowel inventory of CS is shaped as an effect of those relatively high-ranked FCCs. One way to prevent using the two place

\footnotetext{
7 We compare the two approaches in $\S 4$.

8 A discussion of whether it is $\mathrm{UG}$ that provides a universal set of monovalent abstract features goes beyond the scope of this paper.

9 See Levelt and Van Oostendorp (20107) for a full explanation of how features are acquired and how FCCs shape the changing segment inventory throughout the developing stages of language acquisition.

10 In the following, if necessary, we abstract away from place and height distinctions by using the cover features $\{$ PLACE $\}$ and $\{$ HEIGHT $\}$ to refer to either $\{$ front $\}$ or $\{$ back $\}$ and $\{$ high $\}$ or \{low $\}$ indistinctly.
} 
Table 1 All combinations of the features $\{$ high $\},\{$ low $\},\{$ front $\}$ and $\{$ back $\}$ and the effects of high-ranked FCCs $*\{$ front, back $\}, *\{$ high,low $\},\{$ high $\} \Rightarrow\{$ PLACE $\}$ and $\mathrm{V} \Rightarrow\{$ HEIGHT $\}$ on the phonemic inventory

\begin{tabular}{|c|c|c|c|c|}
\hline$\emptyset$ & $\begin{array}{l}\{\text { high }\} \\
\{\text { low }\} \sim / a / \\
\text { front }\} \\
\{\text { back\} }\end{array}$ & $\begin{array}{l}\text { \{high,low } \\
\text { \{high,front }\} \sim / \mathrm{i} / \\
\text { \{high, back } \sim / \mathrm{u} / \\
\text { \{low,front }\{\sim / \mathrm{E} / \\
\text { \{low, back } \sim / \mathrm{O} / \\
\text { front,back }\end{array}$ & $\begin{array}{l}\text { \{high,low, front }\} \\
\{\text { high,low, back\} } \\
\text { \{high,front,back }\} \\
\text { \{low, front,back }\end{array}$ & $\{$ high,low, front, back $\}$ \\
\hline
\end{tabular}

features and thus have a fully economical system with only three features, instead of four features, would be to assume that [a] is surface empty. However, the patterns observed in vowel epenthesis (see 33 and 34) present evidence against this alternative approach, which would predict that [a] is always inserted as an epenthetic vowel, contrary to the facts. The traditional interpretation of the feature sets in terms of underlying segments is illustrated as well. Notice that the $\{$ low,PLACE segments need not necessarily be mid-open vowels phonetically. They do differ from the exclusively low vowel and the high vowels phonologically; phonetically it is likely that these two vowels take up the region that mid-vowels usually occupy. The same inventory of phonemic or contrastive vowels for CS is represented again in (खUI). High-mid vowels are absent in the phonemic inventory of morphemes in CS. The assignment of features follows Dyck (1995): low-mid vowels are $\{$ low $\}$, and they combine with either $\{$ front $\}$ or $\{$ back $\}$ to distinguish them from the placeless low vowel. High vowels are specified for place and for $\{$ high $\}$.

(20) Phonemic CS vowel inventory

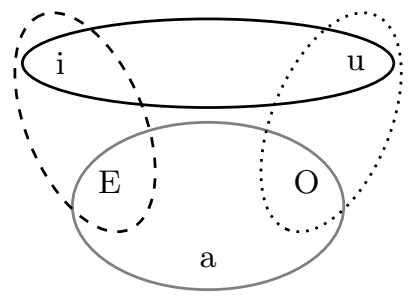

The upcoming analysis of metaphony rests upon the crucial idea that only metaphony-triggering suffixes contain a vowel that is underlyingly specified with the feature $\{$ high $\}$. In contrast, suffixes that do not trigger metaphony are assumed to lack the feature $\{$ high $\}$; instead they comprise of the feature $\{$ low $\}$ (i.e. $/ \mathrm{a} /$ ) or the feature combination \{low,Place (i.e. /E/ or /O/). The specific output realization of each class of suffixes will be explained in the analysis section. It is worth noting that there is no semantic or morphological difference between metaphonizing and non-metaphonizing suffixes. Their difference is etymological. In fact, in Logudorese Sardinian, their difference is still surface-true, because no vowel merger operates in this dialect. In CS, however, vowel merger obscures the alternation of both types of suffixes. In table 2 , the list of metaphonizing and nonmetaphonizing suffixes in CS is given together with their input-output mappings. This table is adapted from Frigeni (2002). 
Table 2 Classes of suffixes (Frigeni ए0102:75)

\begin{tabular}{cccc}
\hline \multicolumn{2}{c}{ metaphonizing } & \multicolumn{2}{c}{ non-metaphonizing } \\
type & $/\{$ high,PLACE $\} /$ & type & $/\{$ low,PLACE $\} /$ \\
\hline M.SG/F.SG & $/-\mathrm{u} \rightarrow[-\mathrm{u}]$ & M.SG/F.SG & $/-\mathrm{E} / \rightarrow[-\mathrm{i}]$ \\
INF.3CONJ & $/-\mathrm{i} / \rightarrow[-\mathrm{i}]$ & M.SG & $/-\mathrm{O} / \rightarrow[-\mathrm{u}]$ \\
IMP.2SG.3CONJ & $/-\mathrm{i} / \rightarrow[-\mathrm{i}]$ & INF.2CONJ & $/-\mathrm{E} / \rightarrow[-\mathrm{i}]$ \\
SUBJUNCTIVE & $/-\mathrm{i} / \rightarrow[-\mathrm{i}]$ & IMP.2SG.2CONJ & $/-\mathrm{E} / \rightarrow[-\mathrm{i}]$ \\
IND.PRES.1PL & $/-(\mathrm{m}) \mathrm{u}(\mathrm{s}) / \rightarrow[-\mathrm{u}]$ & IND.PRES.1SG & $/-\mathrm{O} / \rightarrow[-\mathrm{u}]$ \\
& & ADV.SUFF & $/-\mathrm{E} / \rightarrow[-\mathrm{i}]$ \\
\hline
\end{tabular}

Although we use seemingly standard articulatory-based features, we assume that a direct reference to articulators or a specific phonetic content is irrelevant for phonological computation. Phonological features could therefore be seen as colors, in the sense that they can be mixed to create more complex segments, as elements in Element Theory (Backley 20II). This is why $\{$ high $\}$ and $\{$ low $\}$, for instance, will be shown to be able to surface under certain conditions although this combination is excluded in other contexts.

\subsection{Turbidity Theory}

We aim to account for the opacity in CS metaphony and vowel epenthesis by means of Turbidity Theory (TT, Goldrick 200]; Revithiadou [2007; Van Oostendorp 2008), a strictly parallel, constraint-based model that assumes a containment theory of faithfulness (McCarthy and Prince 199:3). Containment theory in OT assumes that all information present in the input is contained in the output. Therefore, no input material can be deleted in output forms. Deletion is thus accounted for in terms of non-realization, or non-parsing of input material although still present in licit output forms. In TT, which assumes containment, standard linking between root nodes and features is replaced by two distinct types of relations both contained in surface forms: projection relations ( $\uparrow$, i.e. arrows pointing towards the root node), and pronunciation relations ( $\downarrow$, i.e. arrows pointing towards a feature). On the one hand, projection relations express that a feature is lexically linked to a specific root node. On the other hand, pronunciation relations express a surface linking between (lexical) features and root nodes, meaning that the feature is visible at the phonology-phonetics interface by the articulatory system after abstract phonological computation.

The RECIPROCITY constraint family regulates projection-pronunciation relations between features and root nodes locally. By local relations we mean a direct lexical association between a feature and a root node. There are two types of reciprocity constraints. On the one hand, RECIPROCITY $F_{F}^{r}\left(\mathcal{R}_{F}^{r}\right)$ assures that lexical features are realized on the surface. On the other hand, $\operatorname{RECIPROCITY}_{r}^{F}\left(\mathcal{R}_{r}^{F}\right)$ assures that features on the surface correspond to lexical features. Their formal definitions appear in (20). 
(21) ReCiprocity (Van Oostendorp 20108)

a. RECIPROCITY ${ }_{F}^{r}\left(\mathcal{R}_{F}^{r}\right)$ : assign a violation mark for every feature $F$ projected by a root node $r$ that is not pronounced by $r$.

b. RECIPRocity ${ }_{r}^{F}\left(\mathcal{R}_{r}^{F}\right)$ : assign a violation mark for every feature $F$ pronounced by a root node $r$ that is not projected by $r$.

As said, RECIPROCITy constraints regulate the relation between root nodes and features locally. However, in stress-dependent harmony like Italo-Romance metaphony, some features are pronounced by non-local root notes, that is, root nodes other than those that lexically project such features. Therefore, we propose a new family of constraints in TT, LICENSING, which is a less stringent version of RECIPROCITY. These constraints will be shown to be crucial in accounting for the opaque data at hand. This family of constraints regulates projection-pronunciation relations between root nodes and features non-locally ( $[\mathbf{Z Z})$, which means that there is no direct lexical association between the two. As will be shown, these LicEnsing constraints sometimes need to restrict the type of non-local relation that is allowed between a projected feature and the root node that pronounces it non-locally. We will follow Walker (2010.5, 2011) in considering metrically prominent positions as the optimal environments for licensing.

\section{(22) LiCEnsing}

a. LiCEnsing $\uparrow F(\mathcal{L} \uparrow F)$ : assign a violation mark for every projection relation $\uparrow$ of a feature $F$ that does not correspond to some pronunciation relation $\downarrow$ of $F$.

b. LICENSING $\downarrow F(\mathcal{L} \downarrow F)$ : assign a violation mark for every pronunciation relation $\downarrow$ of a feature $F$ that does not correspond to some projection relation $\uparrow$ of $F$.

Features linked to root nodes by a projection relation are always contained in surface representations as are the projection relations themselves; they cannot be deleted by the GEN component of a TT grammar. GEN only includes the following set of operations: (i) insertion of a pronunciation relation $\downarrow$, and (ii) insertion of a feature $F$ together with its pronunciation relation $\downarrow$.

In a TT grammar with privative features, an unfaithful mapping might be the result of not pronouncing a (projected) feature. Non-pronunciation is triggered by the satisfaction of feature co-occurrence constraints (FCCs) of the type $*\{F, G\}$, with the special case ${ }^{*} F$, which are violated whenever a (cluster of) feature(s) is pronounced irrespective of projection relations (Levelt and Van Oostendorp 2007]; Van Oostendorp 2014).

If a particular phonological system makes use of the feature $F$, then an input where $F$ is projected by a root node $r$ must map onto an output where $F$ is pronounced. This mapping is possible if at least RECIPROCITY ${ }_{F}^{r}$ or $\operatorname{LiCENSING} \uparrow F$ dominates ${ }^{*} F($ (2:3-[24) $)$. The symbols $r$ and $s$ stand for root nodes, the latter following the former. 
(23) Local pronunciation of feature $F$

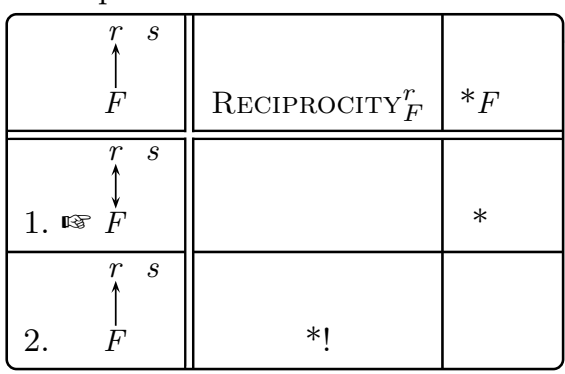

(24) Non-local pronunciation of feature $F$

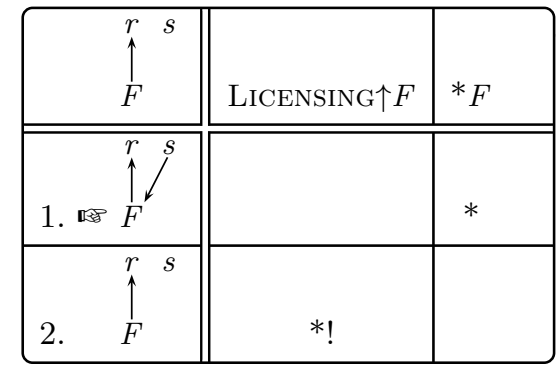

If a phonological system does not make use of $F$, then ranking ${ }^{*} F$ above RECIPROCITY $_{F}^{r}$ and LiCENSING $\uparrow F$ selects the output where $F$ is not pronounced ([2.5).

(25) Non-pronunciation of feature $F$

\begin{tabular}{|c|c|c|c|}
\hline$\stackrel{\uparrow}{F}_{F}^{r}$ & ${ }^{*} F$ & $\operatorname{RECIPROCITY}_{F}^{r}$ & $\begin{array}{ll} \\
\text { LiCENSING } \uparrow F\end{array}$ \\
\hline 1. ${ }^{r} s$ & & $*$ & $\begin{array}{c}1 \\
\vdots \\
1 \\
1 \\
1\end{array}$ \\
\hline 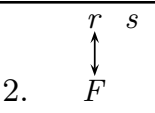 & *! & & \\
\hline 3. $\prod_{F}^{r s}$ & *! & $*$ & \\
\hline
\end{tabular}

Besides FCCs of the type $*\{F, G\}$, implicational constraints can also be responsible for another kind of unfaithful mapping: a local pronunciation of a nonprojected feature $G$ in the presence of a feature $F$ (Van Oostendorp 2014).

To recapitulate, feature co-occurrence markedness constraints come in two forms. A feature $F$ repels a feature $G(*\{F, G\})$ and the presence of a feature $F$ demands the presence of a feature $G(F \Rightarrow G)$. ${ }^{\text {W }}$ These constraints combined

11 One reviewer asks whether there is a principled motivation for the parallel presence of mirror-images of implicational constraints. We do not claim that mirror-image constraints should or should not be active in the same grammar. Their effects can be completely unrelated. For instance, $\{$ PLACE $\} \Rightarrow\{\text { high }\}_{\text {UnSTR }}$ has the effect of neutralising a lexical contrast between 
with RECIPROCITY and LiCENSING constraints are responsible for both generating the segmental inventory of a language and also triggering or blocking languageparticular phonological processes. We also assume that these constraints are sensitive to metrical positions like foot heads and unstressed syllables. We will illustrate the interaction of these constraints in the following section.

\subsection{The metaphony-triggering constraint}

Since the advent of Optimality Theory, vowel harmony has been attributed to several different constraints: alignment, sharing, agreement by correspondence (see Gafos and Dye 201]; Rose and Walker 2010 for detailed references) and featurevalidation (Nevins 2010). Here we propose to interpret the metaphony-triggering constraint as a specific instantiation of a LICENSING $\uparrow$ constraint relativized to the foot head position ( $(26)$.

(26) Metaphony-triggering constraint as a licensing constraint

LiCENSING $\uparrow\{\text { high }\}_{\text {UNSTR }} /$ FTHD $\left(\mathcal{L} \uparrow\{\text { high }\}_{\text {UNSTR }}\right)$ : assign a violation mark for every projection relation $\uparrow$ of a feature $\{$ high $\}$ in an unstressed position that does not correspond to some pronunciation relation $\downarrow$ of $\{$ high $\}$ in a foot head position.

A similar constraint is proposed in Walken (2005), according to which metaphony has a functional basis in improving perceptibility of height features in a posttonic position by associating them with perceptually stronger prosodic positions ([27).

(27) Walker (2005)'s metaphony-triggering constraint

LiCENSE $([+ \text { high }])_{\text {Post-Tonic, }}{ }^{\prime} \sigma$ : [+high] in a post-tonic syllable must be associated with a stressed syllable.

Walker (2005) remains neutral with respect to cases of opacity in which vowel merger counterbleeds vowel raising. After historical vowel merger, the motivation for metaphony as proposed in Walker (2005) can no longer be interpreted as driven by functional forces. Our claim is that, in the synchronic grammar, metaphony is re-interpreted as a licensing condition in terms of projection relations.

metaphonizing and non-metaphonizing suffixes on the surface. In contrast, a constraint like $\{$ high $\} \Rightarrow\{$ PLACE $\}$ just bans central high vowels from the vowel inventory of CS. The outcome of the two constraints is not equivalent; therefore, we need both constraints. Another reviewer wondered whether these implicational constraints are ad hoc or whether they reflect some kind of relation between features. We believe that not all logical combinations of features create FCC constraints of the type $*\{F, G\}$ or constraints of the type $F \Rightarrow G$. Their existence should follow from a developed theory of feature representations (maybe feature geometry is an adequate framework). Generally, we see implicational constraints as a more refined version of standard OT constraints such as * glottal stop or *schwa, which are usually used as cover constraints referring to clusters of features. We think that implicational constraints are less stipulative than formulations like *schwa since they make reference to combinations of two features only. An advantage of this approach is that we avoid mixing constraints that refer to features with constraints that refer to whole segmental units or clusters of more than two features within one OT grammar. Implicational constraints therefore hold promise for developing an explanatory theory of markedness. 


\section{Analysis}

First we consider those inputs containing a metaphonizing suffix, that is, with an underlying $\{$ high $\}$ feature, affixed to a root vowel consisting of the features $\{$ PLACE $\}$ and $\{$ low $\}$, i.e. a low-mid vowel. The projection relation $\uparrow$ of the feature $\{$ high $\}$ associated to the suffix must be licensed by some pronunciation relation $\downarrow$ in the foot head position to satisfy the constraint LICENSING $\uparrow\{\text { high }\}_{\text {UNSTR }} /$ FTHD. This is illustrated by candidate (1) in tableau ( $(\mathbf{Z Z})$, in which the root vowel ends up pronouncing three features, $\{$ PlaCE $\},\{$ low $\}$ and $\{$ high $\}$. The pronunciation of $\{$ high $\}$ by the root vowel violates the feature co-occurrence constraint $*\{$ high,low $\}$, which prohibits high-mid vowels, and the constraint RECIPROCITY ${ }_{V}^{\{h i g h\}}$, which penalizes the pronunciation of the feature $\{$ high $\}$ by a root node that does not project that feature. Candidate (2) is the faithful candidate, which is ruled out by the high-ranked metaphony-triggering constraint LiCENSING $\uparrow\{\text { high }\}_{\text {UNSTR }} /$ FTHD. RECIPROCITY $V$ llow\} militates against leaving the feature $\{$ low $\}$ unpronounced as shown by candidate 3 . This is why low-mid vowels raise to high-mid vowels instead of high vowels (28).

(28) Metaphony (/or-u/ $\rightarrow$ ['oru] 'edge')

\begin{tabular}{|c|c|c|c|c|c|}
\hline$\underset{\{\mathrm{PL}\}\{\text { low }\}}{\mathrm{V}}-\underset{\{\text { high }\}\{\mathrm{PL}\}}{\mathrm{V}}$ & & $\mathcal{R}_{\{l o w\}}^{V}$ FTHD & $\begin{array}{l}\mathcal{L} \uparrow\{\text { high }\}_{\text {UNSTR }} \\
1\end{array}$ & $*\{$ high,low $\}$ & $\mathcal{R}_{V}^{\{h i g h\}}$ \\
\hline 1. & ['oru] & & $\begin{array}{c}1 \\
\vdots \\
\vdots\end{array}$ & $*$ & 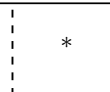 \\
\hline 2. & *['эru] & & $\begin{array}{c}1 \\
1 \\
1 \\
1 \\
1\end{array}$ & & \\
\hline 3. & $*[$ 'uru] & $* !$ & $\begin{array}{c}1 \\
\vdots \\
1\end{array}$ & & $\begin{array}{c}1 \\
1 \\
1 \\
1\end{array}$ \\
\hline
\end{tabular}

Now we can illustrate the surface vowel inventory of CS, which incorporates high-mid vowels. High-mid vowels include all the features that identify low-mid vowels plus the feature $\{$ high $\}$, as shown in (खq) .

(29) Surface CS vowel inventory

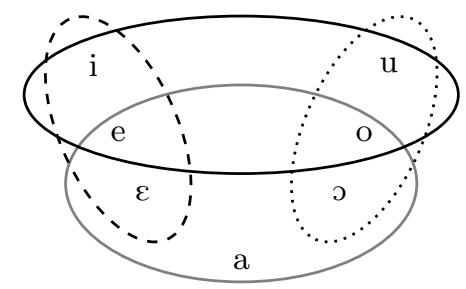

As opposed to low-mid vowels, low vowels are not targeted by metaphony. This means that if a metaphony-triggering suffix is attached to a root containing a low vowel, the projection relation of the feature $\{$ high $\}$ cannot be licensed by the root vowel. If the feature $\{$ high $\}$ is licensed by the low vowel, the pronunciation of this feature creates a configuration where $\{$ high $\}$, but not $\{\mathrm{PLACE}\}$, is present. This 
configuration violates $\{$ high $\} \Rightarrow\{$ PLACE $\}$, as candidate (3) in tableau (BU) illustrates (interpretable as a high-mid central unrounded or rounded vowel). This implicational constraint expresses the fact that place distinctions are required for high vowels. It can be satisfied by inserting the feature $\{$ PLACE $\}$, which violates RECIPROCITY $_{V}^{\{\text {PLACE }\}}$, as shown by candidate (2) (interpretable as a high-mid front or back vowel). The blocking effect of low vowels is obtained by ranking these two constraints above the metaphony-triggering constraint LICENSING $\uparrow\{\text { high }\}_{\text {UNSTR }} /$ FTHD. A potential way to satisfy the metaphony-triggering constraint could be to lower the suffix vowel, that is, leaving the feature $\{$ high $\}$ unpronounced. However, the undominated position of the constraint $\{$ PLACE $\} \Rightarrow\{\text { high }\}_{\text {UNSTR }}$ (cf. B.5), which requires pronouncing the feature $\{$ high $\}$ in the presence of $\{$ PLACE $\}$ in suffixal position, discards the possibility of suffix vowel lowering.

(30) Low vowel as non-undergoer $\left(/ \varepsilon\right.$ dad-i/ $\rightarrow\left[\varepsilon^{\prime}\right.$ ðaði $]$ 'age')

\begin{tabular}{|c|c|c|c|c|}
\hline 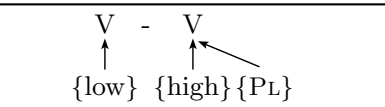 & & $\{$ high $\} \Rightarrow\left\{\mathrm{PL}_{\mathrm{L}}\right\}$ & $\mathcal{R}_{V}^{\{\mathrm{PL}\}}$ & $\mathcal{L} \uparrow\{\text { high }\}_{\text {UNSTR }}$ \\
\hline 1. $\downarrow_{\{\mathrm{low}\}}^{\mathrm{V}} \overbrace{\{\mathrm{high}\}}^{\mathrm{V}}\{\mathrm{PL}\}$ & [ع'ðаðі] & & & * \\
\hline$\{\mathrm{PL}\}\{\mathrm{low}\}\{$ high $\}\{\mathrm{PL}\}$ & $*\left[\varepsilon^{\prime}\right.$ ðе/oði $]$ & & $* !$ & \\
\hline 3. & *[ع'ð૭/өði] & $* !$ & & \\
\hline
\end{tabular}

Now we will consider the opaque cases where metaphony underapplies. Underapplication is due to the fact that non-metaphonizing suffixes lack a specification for the feature $\{$ high $\}$ and only contain the feature $\{$ PLACE $\}$ and $\{$ low $\}$. The faithful candidate (3) in (Bत) in which the suffix surfaces as a $\{$ high\}-less suffix that is only specified for place and $\{l o w\}$ is ruled out by the implicational constraint $\{$ PLACE $\} \Rightarrow\{\text { high }\}_{\text {UNSTR }}$, which triggers the insertion of the feature $\{$ high $\}$ in vowels occupying an unstressed position. That is, mid vowels never surface in suffixal positions. This implicational constraint must be relativized to refer to unstressed positions because insertion of $\{$ high $\}$ is not required in stressed positions, where low-mid vowels surface. Diachronic vowel merger is therefore interpreted in synchronic grammars as a general implicational constraint, which must be ranked above RECIPROCITY $V_{V}^{\{h i g h\}}$. Among the candidates that satisfy the implicational constraint $\{\mathrm{PLACE}\} \Rightarrow\{\text { high }\}_{\text {UnSTR }}(1,2$ and 3$)$, the candidate that does not undergo metaphony and leaves the feature $\{$ low $\}$ unpronounced is the most harmonic candidate. Since the feature $\{$ high $\}$ is an inserted feature without any projection relation, the licensing constraint LICENSING $\uparrow\{\text { high }\}_{\text {UNSTR }} /$ FTHD (omitted in tableau (उप) ) is vacuously satisfied by all candidates. The decision is then left to the FCC $*\{$ high,low $\}$, which disfavors high-mid vowels, or the constraint RECIPROCITY ${ }_{V}$ high $\}$ in the case of candidate (3) - both constraints are unranked with respect to each other. In other words, high-mid vowels do not surface in CS unless an underlying \{high\} feature in a suffix must be licensed via non-local pronunciation in order to satisfy the metaphony-triggering constraint LICENSING $\uparrow\{\text { high }\}_{\text {UNSTR }} /$ FTHD. 
(31) Underapplication of metaphony (/or-っ/ $\rightarrow$ ['əгu] 'gold')

\begin{tabular}{|c|c|c|c|c|}
\hline 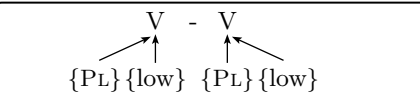 & & $\left\{\mathrm{PL}_{\mathrm{L}} \Rightarrow\{\text { high }\}_{\mathrm{UNSTR}}\right.$ & * 1 high,low $\}$ & $\mathcal{R}_{V}^{\{h i g h\}}$ \\
\hline 1. $\leftrightarrow\left\{\mathrm{PL}_{\{\mathrm{low}\}}\right.$ & ['วru] & & $\begin{array}{c}1 \\
1 \\
1 \\
1 \\
1\end{array}$ & $*$ \\
\hline 2. & *['oro $]$ & & $\begin{array}{ccc}1 \\
1 \\
1 \\
1 \\
1\end{array}$ & $*$ \\
\hline 3. & $*[$ 'oru $]$ & & $\begin{array}{ccc}1 \\
1 \\
1 \\
1 \\
1\end{array}$ & $* *$ \\
\hline 4. & *['oro] & $* !$ & & \\
\hline
\end{tabular}

In compliance with Richness of the Base (Prince and Smolensky [199:3), an input consisting of a high-mid vowel in a foot head position must be considered. The grammar should prohibit this vowel to surface as such if followed by a low vowel suffix (['vera] 'true-FEM.SG.' $c f$. $*$ ['vera]). The $\{$ high $\}$ feature does not need to be licensed because it is not in an unstressed position. It is the feature co-occurrence constraint $*\{$ high,low $\}$ that rules out the pronunciation of the projected feature $\left\{\right.$ high . This constraint thus dominates the constraint RECIPROCITY ${ }_{\{h i g h\}}^{V}$

(32) Blocking of high-mid vowels (*['vera] 'true-FEM.SG.')

\begin{tabular}{|c|c|c|c|}
\hline$\overbrace{\{\mathrm{PL}\}\{\mathrm{low}\}\{\text { high }\}}^{\mathrm{V}}-\uparrow_{\{\mathrm{low}\}}^{\mathrm{V}}$ & & $*\{$ high, low $\}$ & $\mathcal{R}_{\{h i g h\}}^{V}$ \\
\hline 1. & ['vera] & & $*$ \\
\hline$\underset{\{\mathrm{PL}\}\{\text { low }\}\{\text { high }\}}{\longrightarrow}-\mathrm{v}$ & $*[$ 'vera $]$ & $* !$ & \\
\hline
\end{tabular}

Recall that high-mid vowels are exclusively specified for place in Dyck (ए995). An input form containing a high-mid vowel specified for $\{$ PLACE $\}$ must therefore not surface as such in CS. The implicational constraint responsible for excluding high-mid vowels in contexts other than the metaphonic one is $\mathrm{V} \Rightarrow\{$ HEIGHT $\}$, as explained prior to table $\square$.

Lastly, we will explain how the quality of vowel epenthesis is obtained. ${ }^{[2}$ Only two additional constraints, of the types introduced in this paper, are enough to

\footnotetext{
12 As was shown by our newly collected data, word-final codas were prohibited at both the phonological word-edge domain and the phonological phrase-edge domain. Two repair strategies were observed: vowel epenthesis and consonant deletion. Consonant deletion was only possible phrase-medially, and utterance-final consonants were always avoided by means of vowel epenthesis. It is not the goal of this paper to account for this variation and the factors that lie behind it, although we are the first in describing this situation for vowel epenthesis in $\mathrm{CS}$ as far as we know. We leave this topic for future research.
} 
account for the quality of vowel epenthesis. After a stressed mid vowel, only the place feature of the stressed vowel, never the $\{$ low $\}$ feature, is interpreted by the epenthetic vowel, and the epenthetic vowel always surfaces as a high vowel, thus complying with the required three-vowel reduced system in post-tonic word-final position. Consider tableau (B:3), in which the vowel preceding the epenthetic vowel is low-mid. As illustrated by candidate (4), one possibility is to insert both the feature $\{$ high $\}$ and the feature $\{$ PLACE $\}$. However, this is discarded because inserting the feature $\{$ PLACE $\}$ fatally violates the top-ranked constraint LICENSE $\downarrow\{$ PLACE $\}$, which is violated whenever a feature $\{$ PLACE $\}$ is not projected by some root node. This candidate is harmonically bounded by the winning candidate, which pronounces the feature $\{$ PLACE $\}$ from the stressed vowel and only inserts $\{$ high $\}$. This explains why place is always shared between the stressed mid vowel and the epenthetic vowel. If $\{$ PLACE $\}$ were freely inserted, the place-identity could remain unexplained. Another possible output is candidate (2), with insertion of $\{$ high $\}$ but no pronunciation of $\{\mathrm{PLACE}\}$. This is not possible because of the constraint $\{$ high $\} \Rightarrow\{$ Place $\}$, which dominates ReCIProcity ${ }_{V}^{\{\text {PlaCE }\}}$. Another potential candidate, candidate (3), only pronounces the feature $\{$ low $\}$. This outcome is ruled out by ranking RECIPROCITY ${ }_{V}^{\{l o w\}}$ above RECIPROCITY ${ }_{V}^{\{\mathrm{PLACE}\}}$.

(33) Partial vowel epenthesis (['sczi] 'you are')

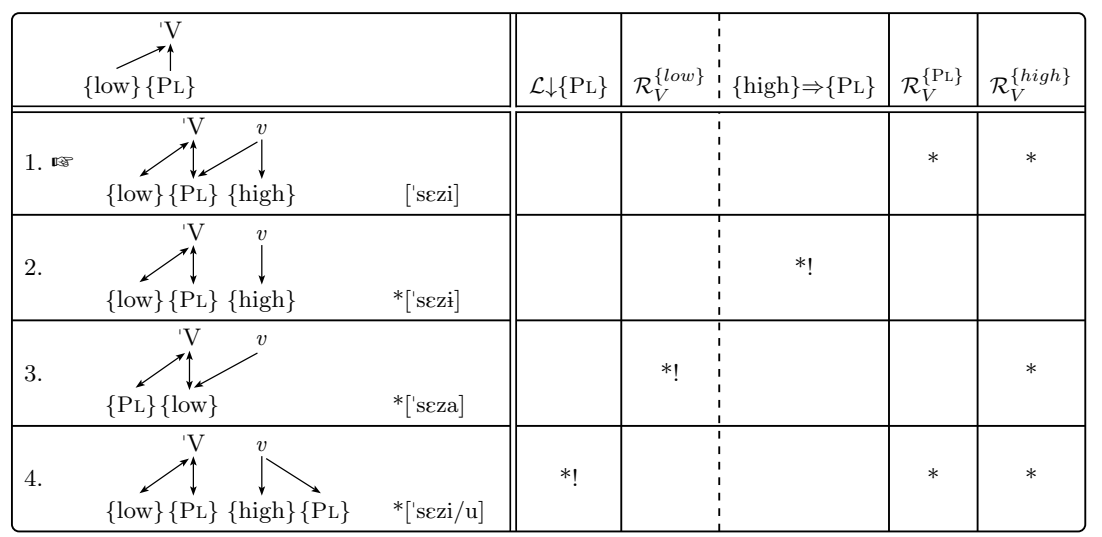

When the source vowel is low, no feature $\{$ high $\}$ is inserted and the epenthetic vowel surfaces as a low vowel. Recall that the pronunciation of the feature $\{$ high $\}$ always involves the pronunciation of the feature $\{\mathrm{PLACE}\}$ due to the top-ranked constraint $\{$ high $\} \Rightarrow\{$ PLACE $\}$ (omitted in tableau (Bप) and satisfied by the two candidates). In the absence of the projection of the feature $\{$ PLACE $\}$ by the stressed vowel, pronouncing it would incur a violation of LICENSING $\downarrow\{$ PLACE $\}$, which is topranked in the hierarchy. This constraint is still not satisfied if the feature $\{$ PLACE $\}$ is pronounced by the root vowel, as shown by candidate (3). This way, pronouncing the feature $\{$ low $\}$ is the only possibility left, showing that LICENSING $\downarrow\{$ PLACE $\}$ dominates RECIPROCITY $V_{V}^{\{l o w\}}$ (西更). 
(34) Full vowel epenthesis from a low vowel (['rozaza] 'roses')

\begin{tabular}{|c|c|c|c|}
\hline $\begin{array}{c}\mathrm{V} \\
\uparrow \\
\{\text { low }\}\end{array}$ & & $\mathcal{L} \downarrow\{\mathrm{PL}\}$ & $\mathcal{R}_{V}^{\{\text {low }\}}$ \\
\hline 1. & ['rozaza] & & $*$ \\
\hline$\downarrow$ & *['rozazi/u] & $* !$ & \\
\hline$\underset{\{\text { low }\}\{\mathrm{PL}\}\{\text { high }\}}{\mathrm{V}}$ & *['roze/ozi/u] & $* !$ & \\
\hline
\end{tabular}

When the vowel preceding the epenthetic vowel is high, the feature $\{$ PLACE $\}$ is available. This is why the feature $\{$ PLACE $\}$ can be pronounced by the epenthetic vowel without violating LiCENSING $\downarrow\{$ PLACE $\}$, as well as $\{$ high $\}$, whose pronunciation is possible given the low ranking of RECIPROCITY $V_{V}^{\{h i g h\}}$.

To sum up, all the ranking arguments presented so far are represented as a Hasse diagram in (3.5).

(35) CS grammar as a Hasse diagram

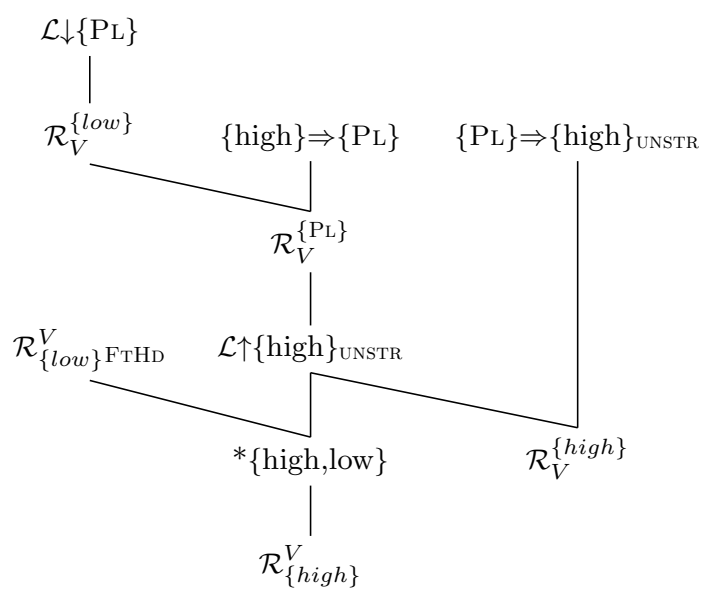

An important aspect of this analysis is that the very same constraints that are necessary for shaping the segmental inventory of the language are also responsible for the quality of epenthetic vowels, as well as for the application and non-application of metaphony.

In our approach, we assume both feature privativity and Turbidity Theory. The combination of the two is crucial for explaining the opaque patterns. On the one hand, the use of privative features allows for representing non-metaphonizing suffixes as lacking a projected feature $\{$ high $\}$ (see tableau $\amalg$ U). On the other hand, Turbidity Theory allows for making a distinction between projected (lexical) and 
pronounced (surface) features. Both assumptions, privativity and Turbidity Theory, are necessary to derive the pattern of underapplication of metaphony (/or-ə/ $\rightarrow$ ['oru] 'gold'). Because of Turbidity Theory, the metaphony-triggering constraint can be formulated in a way that only makes reference to projected features. For instance, if binary features and $\{+\mathrm{ATR}\}$ as the feature causing metaphony in CS were assumed, vowel merger would be the result of changing the value of $\{$ ATR $\}$ from - to + . Once vowel merger applies, what could block the spreading of $\{+$ ATR $\}$ ? Using Turbidity Theory would not help because the projection-pronunciation relation is a function of features, not of values. We conclude that this problem can only be solved if vowel merger is the result of pronouncing a privative feature that is not present underlyingly.

\section{Typological implications}

This section is devoted to the exploration of the typological implications of our analysis. To do so, we used OT-Help 2.0 (Staubs et al. 2010), a software that calculates factorial typologies in OT.

We considered two possible inputs: a root containing a low-mid front vowel $/ \varepsilon /$ and a root containing a high-mid front vowel /e/ both followed by a high vowel suffix /-i/. Since front and back vowels usually show a symmetrical behavior, we only focused on front vowels. .3

The set of constraints that were fed to OT-Help 2.0 are the ones proposed for CS. This constraint set includes all RECIPROCITY constraints for the features $\{$ high $\}$ and $\{$ low $\}$, the metaphony-triggering constraint LICENSING $\uparrow\{\text { high }\}_{\text {UNSTR }} /$ FTHD, and the feature co-occurrence constraint $*\{$ high,low $\}$. We use these constraints to explore the effects that constraint permutation has on the attested typology of metaphonic patterns.

For the output candidates, we always allowed the faithful candidates (stressed $[\varepsilon, \mathrm{e}]$ belonging to the root) and the candidate displaying metaphony (stressed [i] belonging to the root). As opposed to CS, most Italo-Romance varieties have a seven-vowel system. According to Dyck's ([9.95) proposal as shown in (15), highmid vowels in four-height systems are only specified by a place feature, either \{front $\}$ or $\{$ back $\}$. However, as claimed in our analysis, high-mid vowels can also receive a more complex specification of features, that is, PLACE,high,low . This alternative specification for high-mid vowels was also included as an additional fourth candidate. We claim that the same phonetic realization can derive from two different phonological specifications depending on how phonological systems are organized. We will be more specific about this point after presenting the results of constraint permutation.

\footnotetext{
13 We excluded the root low vowel /a/ as a possible input since this vowel is hardly ever affected by metaphony in Italo-Romance. One dialect showing /a/ raising, though, is the Ischia dialect (see Krämer [2016).
} 
(36) Factorial typology

\begin{tabular}{|c|c|c|c|}
\hline$/ \varepsilon-\mathrm{i} /$ & $/ e-i /$ & Pattern & Dialect \& Ranking \\
\hline \multirow[t]{2}{*}[\varepsilon-i]{} & {$[e-i]$} & No metaphony & Standard Italian \\
\hline & & & $\mathcal{R}_{\{l o w\}}^{V}, \mathcal{R}_{\{\text {high }\}}^{V},{ }^{*}\{$ high,low $\}, \mathcal{R}_{V}^{\{\text {high }\}}, \mathcal{R}_{V}^{\{l o w\}} \gg \mathcal{L} \uparrow\{\text { high }\}_{\text {UNSTR }}$ \\
\hline \multirow[t]{2}{*}[\varepsilon-\mathrm{i}]{} & {$[\mathrm{i}-\mathrm{i}]$} & Restricted metaphony & Grado (Walker Zu10.5) \\
\hline & & & $\mathcal{R}_{\{\text {low }\}}^{V}, \mathcal{R}_{\{\text {high }\}}^{V},{ }^{*}\{$ high, low $\}, \mathcal{R}_{V}^{\{l o w\}} \gg \mathcal{L} \uparrow\{\text { high }\}_{\text {UNSTR }} \gg \mathcal{R}_{V}^{\{h i g h\}}$ \\
\hline \multirow[t]{2}{*}[\mathrm{i}-\mathrm{i}]{} & {$[\mathrm{i}-\mathrm{i}]$} & Metaphony & Foggiano (Calabrese 2011$)$ \\
\hline & & & $\mathcal{L} \uparrow\{\text { high }\}_{\text {UNSTR }}, \mathcal{R}_{\{\text {high }\}}^{V}, *\{$ high, low $\}, \mathcal{R}_{V}^{\{l o w\}} \gg \mathcal{R}_{\{\text {low }\}}^{V}, \mathcal{R}_{V}^{\{h i g h\}}$ \\
\hline \multirow[t]{2}{*}[e-i]{} & {$[\mathrm{i}-\mathrm{i}]$} & Gradual raising & 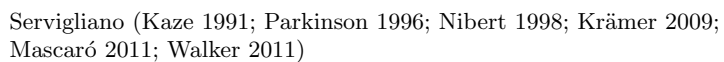 \\
\hline & & & $\mathcal{L} \uparrow\{\text { high }\}_{\text {UNSTR }}, \mathcal{R}_{\{l o w\}}^{V}, \mathcal{R}_{\{\text {high }\}}^{V}, \mathcal{R}_{V}^{\{l o w\}} \gg *\{$ high, low $\}, \mathcal{R}_{V}^{\{h i g h\}}$ \\
\hline
\end{tabular}

Four types of patterns, illustrated in (\$6), are the result of the OT-Help 2.0 computation. There are no other rankings that derive other grammars. The four possible types correspond to attested metaphonic patterns in Italo-Romance. ${ }^{\text {"4 }}$ The first pattern shows no metaphony (cf. Standard Italian). This is due to the fact that the metaphony-triggering constraint LICENSING $\uparrow\{\text { high }\}_{\text {UNSTR }} /$ FTHD is outranked by all other RECIPROCITY constraints and $*\{$ high,low $\}$. The second pattern corresponds to what we have called restricted metaphony. In this pattern, only highmid vowels are affected by metaphony, whereas low-mid vowels remain unaltered. This pattern can be illustrated with data from Grado (B7).

(37) Grado (Walker 2005)

$\begin{array}{llll}\mathrm{t}[\text { 'e]mp-o } & \text { 'time' } & \mathrm{t}[\text { 'i] } \mathrm{mp}-\mathrm{i} & \text { 'times' } \\ \mathrm{s}[\text { 'o]rd-o } & \text { 'deaf-MASC.SG' } & \mathrm{s}[\text { 'u]rd-i } & \text { 'deaf-MASC.PL' } \\ \mathrm{b}[\text { ' } \varepsilon] \text { l-o } & \text { 'beautiful-MASC.sG' } & \mathrm{b}[\text { ' } \varepsilon] \text { ]-i } & \text { 'beautiful-MASC.PL' } \\ \mathrm{m}[\text { 'o]rt-o } & \text { 'dead-MASC.SG' } & \mathrm{m}[\text { 'o]rt-i } & \text { 'dead-MASC.PL' }\end{array}$

The pattern exemplified with Grado is obtained by ranking the metaphonytriggering constraint above RECIPROCITY ${ }_{V}^{\{h i g h\}}$, all the other rankings being equal. The constraint RECIPRocity $Y_{V}^{\{h i g h\}}$ demands that a pronounced feature $\{$ high $\}$ is projected by the root node. When metaphony applies, this constraint is violated because the root node pronounces the feature \{high \} projected by the suffix, but this violation makes it possible to satisfy the metaphony-triggering constraint. Low-mid vowels are not affected by metaphony because of the high-ranked constraint $*\{$ high,low $\}$.

The third pattern refers to the metaphonic system in which all mid vowels raise to high. This pattern can be illustrated with data from Foggiano in (1), repeated in (38).

(38) Foggiano (Calabrese 1998, 2011)

$\begin{array}{llll}\text { ['kjen-a] } & \text { 'full-FEM.sG' } & \text { ['kjin-u] } & \text { 'full-MASC.SG' } \\ \text { ['mofJ-a] } & \text { 'soft-FEM.sG' } & {\left[\text { 'mu } \int-\mathrm{u}\right]} & \text { 'soft-MASC.sG' } \\ \text { ['pet-e] } & \text { 'foot' } & \text { ['pit-i] } & \text { 'feet' } \\ \text { ['gross-a] } & \text { 'big-FEM.sG' } & \text { ['gruss-u] } & \text { 'big-MASC.sG' }\end{array}$

14 CS does not appear in the typology but it behaves like Servigliano; the only difference is that CS has no contrastive high-mid vowels. 
In this pattern, the metaphony-triggering constraint dominates RECIPROCITY ${ }_{V}^{\{h i g h\}}$; all winning candidates pronounce the feature \{high $\}$ belonging to the suffix although root vowels do not project this feature. The metaphony-triggering constraint also dominates RECIPROCITY ${ }_{\{l o w\}}^{V}$ because low-mid vowels, in order to raise to high, need to get rid of their feature $\{$ low $\}$.

Finally, we get a fourth pattern labeled as gradual raising in which low-mid vowels raise to high-mid, and high-mid vowels raise to high. This is a prototypical case of synchronic chain shift, extensively discussed for Servigliano (Mascaró 201]). The data from Servigliano (2) is repeated in (इप).

(39) Servigliano (Camilli 1929; Mascaró 2011)

$\begin{array}{llll}\text { ['pes-a] } & \text { 'heavy-FEM.SG' } & \text { ['pis-u] } & \text { 'heavy-MASC.SG' } \\ \text { ['fjor-e] } & \text { 'flower' } & {[\text { 'fjur-i] }} & \text { 'flowers' } \\ \text { ['ped-e] } & \text { 'foot' } & \text { ['ped-i] } & \text { 'feet' } \\ \text { ['mort-a] } & \text { 'dead-FEM.sG' } & \text { ['mort-u] } & \text { 'dead-MASC.SG' }\end{array}$

In this system, the top-ranked position of LiCENSING $\uparrow\{\text { high }\}_{\text {UnSTR }} /$ FTHD induces metaphony. With a low-mid input vowel, the undominated position of $\mathcal{R}_{\{l o w\}}^{V}$ prevents the feature $\{$ low $\}$ from being unpronounced; this is why the optimal output vowel pronounces both $\{$ high $\}$ and $\{$ low . However, with a high-mid input vowel, specified exclusively for $\{$ front $\}$, the pronunciation of the feature $\{$ high $\}$ from the suffix vowel triggers metaphony.

Synchronic chain shifts of this type are examples of counter-feeding opacity, in which the output of one process, in this case low-mid vowel raising, fails to feed another process, in this case high-mid vowel raising. In the model proposed in this paper in which there is no one-to-one relationship between phonological representations and specific phonetic realizations, this kind of opaque chain shift can be accounted for. This assumption is in line with other recent studies acknowledging the existence of dissimilarities between phonology and phonetics; for a discussion on substance-freedom in phonology, that is, the fact that phonological computation is independent from phonetic interpretation, see Clements 2001; Blaho 2008; Odden 2006, 2013; Hale and Reiss 2008; Mielke 2008; Iosad 2012;

\footnotetext{
15 Given Richness of the Base, we should also consider the possibility of a high-mid input vowel specified as the derived high-mid vowel containing the features front,high,low . We included this potential input vowel; yet, the same set of four possible metaphonic patterns (as in 56) was derived. For the more complex high-mid input vowel, however, different outcomes were derived by the individual grammars: in some systems this vowel raises to high (metaphony applies), and in other systems it maps faithfully as such (no metaphony applies to it). When it raises to high, the less complex high-mid input vowel only including $\{$ front $\}$ also raises to high. So, metaphony never exclusively applies to the more complex high-mid input vowel. Alternatively, when the complex high-mid vowel \{front,high,low $\}$ maps faithfully as such, the less complex high-mid vowel \{front\} either raises to high or maps faithfully as \{front $\}$. The former case, in which the less complex high-mid vowel front\} raises to high but the complex high-mid vowel \{front,high,low $\}$ does not, might appear pathological - although we reject such an interpretation. Richness of the Base says that there are no language-specific restrictions on inputs. However, this of course does not mean that morphemes can have more than one underlying representation. With respect to the more complex high-mid vowel, we hypothesize that there is no morpheme with the lexical representation \{front,high,low , possibly due to lexicon optimization. Such a representation is only possible as derived high-mid vowels from low-mid vowels, as illustrated for CS. In the end, what is crucial is that the same four metaphony patterns illustrated in (उत) were obtained even if high-mid input vowels specified for $\{$ front,high,low $\}$ were included.
} 
Youssef 20113; Hamann 2014. The difference of this pattern with respect to the one in which metaphonic outcomes are only high vowels is the position of the feature co-occurrence constraint $*\{$ high,low $\}$, which is violated. Also, in this pattern the constraint RECIPROCITY $V$ low\} \{low cannot be left unpronounced, as in the restricted metaphony pattern.

The constraint set presented so far derives a typology that matches the attested patterns of metaphony. This typology is drawn from Maiden ([987), although simplified, and it is not intended to cover those metaphonic patterns found in the Iberian peninsula ( $c f$. Penny 20109). According to Maiden ([1987), metaphony of lower vowels presupposes metaphony of higher vowels, and this is what our typology covers. However, it is not the purpose of this paper to explain the other three implications found in Italo-Romance metaphony: (i) that metaphony in closed syllables pressuposes metaphony in open syllables but not the other way around, (ii) that if, for a specific vowel, metaphony is restricted to open syllables, it will apply to both open and closed syllables in any other higher vowel, and (iii) metaphony triggered by word-final / $\mathrm{u} /$ presupposes metaphony triggered by word-final /i/, but not vice versa. What the proposed representational assumptions and set of constraints rightly predict is that there are no patterns in which metaphony for any vowel does not presuppose metaphony in any higher vowel. As a matter of illustration, a metaphonic pattern in which, for instance, low-mid vowels are targeted by metaphony $(/ \varepsilon / \rightarrow[\mathrm{i}])$ but not high-mid vowels $(/ \mathrm{e} / \rightarrow[\mathrm{e}])$ cannot be derived in our model ${ }^{\mathbb{6}}$ Also, a step-wise metaphonic pattern rising the low-mid vowel to high-mid $(/ \varepsilon / \rightarrow[\mathrm{e}])$, but leaving high-mid vowels unaffected $(/ \mathrm{e} / \rightarrow[\mathrm{e}])$, is not derived either. ${ }^{\square}$ Finally, it is worth mentioning, as pointed out in Walker (2005), that a potential solution of licensing in prosodically weak positions could be a stress shift to the suffix. Nothing prevents a ranking in OT in which the metaphony-triggering constraint and the RECIPROCITY constraint against spreading outrank the constraint responsible for stress assignment. Such a strategy is, however, unattested. This specific case of the too-many-solutions problem is not intrinsic to our model, but a general problem in parallel OT also acknowledged in Walker (2005).

\footnotetext{
16 As said, metaphony of lower vowels presupposes metaphony of higher vowels. However, Old Romanesco and Surselvan are exceptional in that metaphony is restricted to low-mid vowels (Maiden 1987). Krämen (2016) connects this exceptional behavior with the process of vowel reduction in Standard Italian and other dialects, whereby low-mid vowels raise to highmid in unstressed position. Although metaphony targets vowels in stressed position, one could hypothesize that only low-mid vowels are affected by metaphony in those exceptional systems because low-mid vowels are more marked than high-mid vowels in the metaphonic context. An analysis of such patterns goes beyond the scope of this paper. In any case, it is worth mentioning that a pattern in which metaphony is restricted to low vowels is not attested, and the generalization that metaphony of lower vowels implies metaphony of higher vowels cannot therefore be underestimated.

17 One reviewer made us aware of the dialect of Sora (Merlo 1919), with Servigliano-like chain shift plus overapplication of metaphony due to vowel reduction to schwa in suffixes. Our model can straightforwardly account for this pattern. Metaphony still applies in Sora because the high feature associated to the suffix spreads onto the root vowel despite being unpronounced by the suffix due to vowel reduction. Therefore, the metaphony-triggering constraint dominates the RECIPROCITY constraint against pronouncing a feature $\{$ high $\}$ that is not projected by the root vowel. A positional markedness constraint against pronouncing the feature $\{$ high $\}$ in suffixal position must also dominate the reciprocity constraint against leaving a projected feature $\{$ high $\}$ unpronounced in order to account for vowel reduction to schwa. A similar pattern is also found in the dialect of Arpinate (Calabrese 1998; Parodi 18.92).
} 


\section{Discussion}

\subsection{Discussion of Frigenil (20102)}

Our main proposal is that metaphonizing and non-metaphonizing suffixes, although they have the same surface representation, differ in their underlying representations with respect to the feature $\{$ high $\}$. We assume that different phonological behavior, i.e. triggering metaphony or not, is sufficient evidence for such a claim. The basic idea of different underlying representations can also be found in Frigeni (2002), although her approach makes a number of additional assumptions that might be problematic from an Optimality-Theoretical perspective. Frigeni analyses metaphony as $\{$ ATR $\}$ spreading from the suffix vowel to the stem vowel. This creates an additional height distinction in the surface stem vowel inventory which underlyingly differentiates three height levels based on the features $\{$ high $\}$ and \{low (see 40 and 40 ). The reduced surface vowel inventory in the suffixal domain is the result of a neutralization process (loss of $\{$ ATR $\}$ ) followed by a phonetic process of enhancement (insertion of \{high $\}$ ) (see 42 ). The stipulation of two separate vowel inventories for stems and desinences, i.e. two inventories that are specified by different features, is inevitable. However, since a strict reading of OT does not allow us to stipulate any non-emerging underlying vowel inventory due to Richness of the Base, such an account is problematic.

(40) Proposed underlying inventories (Frigeni [20(12)

\begin{tabular}{|c|c|c|}
\hline I & $\mathrm{U}$ & $\{$ high $\}$ \\
\hline $\mathrm{E}$ & $\mathrm{O}$ & \\
\hline A & & $\{$ low $\}$ \\
\hline
\end{tabular}

\begin{tabular}{|c|c|c|}
\hline I & $\mathrm{U}$ & $\{\mathrm{ATR}\}$ \\
\hline $\mathrm{E}$ & $\mathrm{O}$ & \\
\hline $\mathrm{A}$ & & $\{$ low $\}$ \\
\hline
\end{tabular}

(41) Metaphony as $\{$ ATR $\}$ spreading (Frigeni 2002)

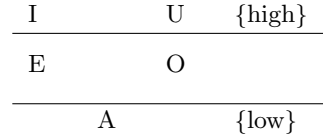

UR stem inventory

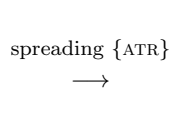

\begin{tabular}{|c|c|c|}
\hline i & $\mathrm{u}$ & $\{$ high $\}$ \\
\hline e & o & $\{$ ATR $\}$ \\
\hline$\varepsilon$ & כ & \\
\hline
\end{tabular}

Surface stem inventory

(42) Vowel reduction as enhancement (Frigeni [20102)

\begin{tabular}{llll}
$\mathrm{I}$ & & $\mathrm{U}$ & $\{$ ATR $\}$ \\
\hline $\mathrm{E}$ & & $\mathrm{O}$ & \\
\hline & $\mathrm{A}$ & & $\{$ low $\}$
\end{tabular}

UR desin. inventory
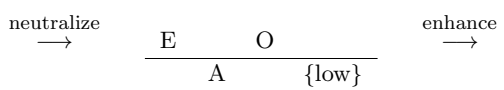

In contrast, we propose that a set of phonologically active features (and all combinations thereof) forms the input to the grammar. The grammar not only accounts for phonological processes such as metaphony but also shapes the surface vowel 'inventory' of a language ( $c f$. section 2.1 and table $\square$ ). Segmental restrictions/differences in certain domains can occur (i.e. a restricted subset of vowels in desinences); however, these restrictions are the result of grammatical computation and are not a stipulated prerequisite. 
Furthermore, it seems that Frigeni's approach relies on extrinsic 'rule' ordering in the sense that desinence-to-stem $\{$ ATR $\}$ spreading must crucially precede neutralization in the desinence inventory, i.e. loss of $\{\mathrm{ATR}\}$, for metaphony to occur in the language at all (see 40 and 42 ). Such a scenario is impossible to implement into parallel OT.

\subsection{Alternative accounts}

The different behaviour of the metaphonizing and non-metaphonizing suffixes could be accounted for by at least two different approaches, featural affixation and lexically-indexed constraints.

\subsubsection{Featural affixation}

Akinlabil (1996); see also Finley 2009 and Wolt 2005) used alignment constraints in which floating features had to be realised onto the stem to account for what Finley (2001) calls morphemic harmony (see also Mascaró 2016).

In cases of overapplication of metaphony, a featural affixation approach using floating features is possible. In Arpinate (Lazio; Calabrese 11998, Parodi [1842), most suffixes neutralized to schwa. Some of these, i.e. the ones that historically originated from high vowels, still trigger metaphony. The underlying representation of these morphemes could be a segment and floating material, i.e. the metaphonizing feature. Then, a realizational constraint would force the floating feature to be realised onto the root. Non-metaphonizing morphemes, which also reduced to schwa but did not originate from high vowels, lack the floating feature.

In CS, however, the floating feature approach is untenable. As opposed to Arpinate, the opacity in CS is of the underapplication type. In CS all suffixes, either metaphonizing or non-metaphonizing, will end up being high. Even if the metaphonizing suffix were represented with a floating feature $\{$ high $\}$, this feature would need to dock onto the suffix. At this point the difference between a floating \{high $\}$ and a linked feature $\{$ high $\}$ would disappear. Therefore, spreading should equally affect both instances of $\{$ high $\}$, contrary to the facts. We conclude that a featural affixation approach to metaphony in CS is not achievable.

The approach to morphemic harmony developed in Finley (200.9) does not necessarily rely on floating features. She proposes an ANCHOR constraint that induces an input feature associated with a specific morpheme to anchor onto a position in the output, either an edge or a prominent position, through correspondence. This type of ANCHOR constraint directly refers to underlying features. The case of underapplication of metaphony in CS could thus be accounted for with an ANCHOR constraint that demands an input feature $\{$ high $\}$ to associate with the stressed vowel in the output. In those cases in which the feature $\{$ high $\}$ is not underlying, but inserted due to vowel reduction requirements, the ANCHOR constraint will be vacuously satisfied and no spreading will take place.

The licensing constraint adopted in our analysis is conceptually equivalent to Finley's ANCHOR constraint because our licensing constraint refers to the projection relation of $\{$ high $\}$, i.e. the underlying status of the feature. Although the two analyses work for CS, TT adds the advantage of being a general theory of phonological opacity. 


\subsubsection{Morpheme-specific licensing}

As we have seen, in CS the masculine singular suffix [-u] behaves non-uniformly: it does not always trigger metaphony. Our proposal is that this morph corresponds to two masculine singular morphemes that receive a different underlying representation: /-u/, the metaphonizing suffix, and /-ऽ/, the non-metaphonizing suffix.

Walker's (2010:159) analysis of the dialect of Francavilla Fontana - in which some morphemes trigger metaphony but others do not - makes use of lexicallyindexed constraints (Pater 2010!9). A lexically-indexed approach needs to assume two different morphemes for the same grammatical features (masculine singular) as we do in our analysis, one marked in the lexicon with an index matching it with the licensing constraint triggering metaphony $(/-\mathrm{u} / \mathrm{L})$ and the other one not indexed $(/-\mathrm{u} /)$. In this respect, a lexically-indexed analysis and our approach are equivalent.

Although an analysis using lexically-indexed constraints works, we think that it misses the fact that lexical indexes are usually used to account for exceptional patterns. Metaphonizing suffixes, however, are as frequent as non-metaphonizing suffixes. Independently from this, we see the problem posed by CS as a case of phonological opacity, not a case of exceptional behavior in phonology.

To sum up, we have explained that the featural affixation approach fails to derive the opaque pattern of metaphony in CS. Both approaches, either based on an ANCHOR constraint or lexically-indexed constraints, could do the job. These approaches put the burden of explanation onto OT computation, whereas our approach exploits representational richness through TT. We hope that our analysis of metaphony in CS contributes to the ongoing debate on the division of labor between representations and computation in OT.

\section{Conclusions}

This paper presented a unified account of different types of opaque interactions between metaphony, vowel merger and vowel epenthesis in CS using feature privativity and Turbidity Theory. We hope that the proposed analysis can contribute to the discussion on the issue of abstractness in phonology, on the one hand, and the role of representations in OT, on the other hand.

Acknowledgements First, we would like to thank the editor of this paper, Rachel Walker, for very detailed comments and corrections on previous versions of this paper, as well as for very helpful guidance throughout the reviewing process. We also want to thank the four anonymous reviewers that helped improving the paper considerably. We would further like to acknowledge the audiences of the 39th Incontro di Grammatica Generativa, Modena and Reggio Emilia, Italy, and the 21st Manchester Phonology Meeting for insightful feedback. Also, we would like to thank the participants of the PhonoLAM reading group in The Netherlands for fruitful discussion on a first manuscript of this paper. Special thanks go to our consultants for the Campidanian Sardianian data: Maria Rita Melis and Ignazia Puddu from Biddecrèsia, Andrea Farras and Rosetta Sanna from Seddori, Antonina Ardia from Sestu, and Amos Cardia from Sìnnia, recorded in April 2013. All unreferenced data in the paper are from these consultants. 


\section{References}

Akinlabi, Akinbiyi. 1996. Featural affixation. Journal of Linguistics 32 (02): 239-289.

Ascoli, Graziadio. 1898. Di un dialetto veneto importante e ignorato. Archivio glottologico italiano 14: 325-355.

Backley, Philip. 2011. An introduction to Element Theory. Edinburgh University Press.

Benus, Stefan, and Adamantios Gafos. 2007. Articulatory characteristics of Hungarian transparent vowels. Journal of Phonetics 35 (3): 271-300.

Blaho, Sylvia. 2008. The syntax of phonology: A radically substance-free approach. PhD diss, University of Troms $\varnothing$.

Bolognesi, Roberto. 1998. The phonology of Campidanian Sardinian: A unitary account of a self-organizing structure. PhD diss, University of Amsterdam.

Calabrese, Andrea. 1985. Metaphony in Salentino. Rivista di grammatica generativa 9-10: $1-140$.

Calabrese, Andrea. 1995. A constraint-based theory of phonological markedness and simplification procedures. Linguistic Inquiry 26 (3): 373-463.

Calabrese, Andrea. 1998. Metaphony revisited. Rivista di Linguistica 10 (1): 7-68.

Calabrese, Andrea. 2011. Metaphony in Romance. In The Blackwell Companion to Phonology, eds. M. van Oostendorp, C. Ewen, E. Hume, and K. Rice, 2631-2661. Malden, MA: WileyBlackwell.

Camilli, Amerindo. 1929. Il dialetto di Servigliano. Archivum Romanicum 13: 220-271.

Clements, G. Nick. 2001. Representational economy in constraint-based phonology. In Distinctive feature theory, ed. T. A. Hall, 71-146. Berlin \& New York: Mouton de Gruyter.

Cole, Jennifer. 1998. Deconstructing metaphony. Rivista di Linguistica 10 (1): 69-98.

Dyck, Carrie. 1995. Constraining the phonology-phonetics interface, with exemplification from Spanish and Italian dialects. PhD diss, University of Toronto.

Finley, Sara. 2009. Morphemic harmony as featural correspondence. Lingua 119 (3): 478-501.

Flack, Kathryn. 2009. Constraints on onsets and codas of words and phrases. Phonology 26 (2): 269-302.

Frigeni, Chiara. 2002. Metaphony in Campidanian Sardinian: A domain-based analysis. Toronto Working Papers in Linguistics 20: 63-91.

Gafos, Adamantios I., and Amanda Dye. 2011. Vowel harmony: Opaque and transparent vowels. In The Blackwell Companion to Phonology, eds. M. van Oostendorp, C. Ewen, E. Hume, and K. Rice, 2164-2189. Malden, MA: Wiley-Blackwell.

Gioscio, Joseph. 1985. Il dialetto Lucano di Calvello. Suttgart: Steiner.

Goldrick, Matthew. 2001. Turbid output representations and the unity of opacity. In NELS 30, eds. M. Hirotani, A. Coetzee, N. Hall, and J. Y. Kim, 231-245. Amherst: GLSA.

Grimaldi, Mirko. 2009. Acoustic correlates of phonological microvariations. In Romance Languages and Linguistic Theory 2006: Selected Papers from 'Going Romance', Amsterdam, 7-9 december 2006, eds. D. Torck and W. L. Wetzels, Vol. 303, 89-109. Amsterdam: John Benjamins Publishing.

Hale, Mark, and C. Reiss. 2008. The phonological enterprise. Oxford: Oxford University Press.

Hamann, Silke. 2014. Mismatches between phonology and phonetics. Invited talk given at the 11th Old World Conference in Phonology.

Iosad, Pavel. 2012. Representation and variation in substance-free phonology: A case study in Celtic. PhD diss, University of Troms $\varnothing$.

Kaze, Jeffrey W. 1991. Metaphony and two models for the description of vowel systems. Phonology 8 (1): 163-170.

Krämer, Martin. 2009. The Phonology of Italian. Oxford University Press.

Krämer, Martin. 2016. Metaphonic chain shifts, vowel height, and markedness. In Approaches to Metaphony in the Languages of Italy, eds. F. Torres-Tamarit, K. Linke, and M. van Oostendorp. De Gruyter Mouton.

Levelt, Claartje, and Marc van Oostendorp. 2007. Feature co-occurrence constraints in L1 acquisition. Linguistics in the Netherlands 24 (1): 162-172.

Maiden, Martin. 1987. New perspectives on the genesis of Italian metaphony. Transactions of the Philological Society 85 (1): 38-73.

Maiden, Martin. 1991. Interactive morphonology: Metaphony in Italy. New York: Routledge.

Mascaró, Joan. 2011. An analysis of stress-dependent harmony in Servigliano. Probus 23 (1): $21-55$.

Mascaró, Joan. 2016. On the typology of metaphony/stress dependent harmony. In Approaches 
to Metaphony in the Languages of Italy, eds. F. Torres-Tamarit, K. Linke, and M. van Oostendorp. De Gruyter Mouton.

McCarthy, John J., and Alan Prince. 1993. Prosodic morphology I: Constraint interaction and satisfaction. Ms., University of Massachusetts, Amherst, and Rutgers University. RuCCSTR-3.

Merlo, Clemente. 1919. Fonologia del dialetto di Sora. Pisa: F. Mariotti.

Mielke, Jeff. 2008. The emergence of distinctive features. Oxford: Oxford University Press.

Nevins, Andrew. 2010. Locality in vowel harmony. Cambridge: MIT Press.

Nibert, Holly J. 1998. Processes of vowel harmony in the Servigliano dialect of Italian: A comparison of two non-linear proposals for the representation of vowel height. Probus 10 (1): $67-101$.

Odden, David. 2006. Phonology ex nihilo. Talk at the Tromsø Phonology Project Group Meeting.

Odden, David. 2013. Formal phonology. Nordlyd 40 (1): 249-273.

Parkinson, Frederick B. 1996. The representation of vowel height in phonology. PhD diss, Ohio State University.

Parodi, Ernesto. 1892. Il dialetto di Arpino. Archivo Glottologico Italiano 13: 299-308.

Pater, Joe. 2009. Morpheme-specific phonology: Constraint indexation and inconsistency resolution. In Phonological argumentation: Essays on evidence and motivation, ed. Steve Parker. London: Equinox Publishing Ltd..

Penny, Ralph. 2009. Vowel harmony and metaphony in Iberia: A revised analysis. Estudos de Lingüística Galega 1: 113-124.

Prince, Alan, and Paul Smolensky. 1993. Optimality Theory: Constraint interaction in generative grammar. Unpublished ms., Rutgers University \& University of Colorado, Boulder. Published 2004, Malden, MA; Oxford: Blackwell.

Revithiadou, Anthi. 2007. Colored turbid accents and containment: A case study from lexical stress. In Freedom of Analysis?, eds. S. Blaho, P. Bye, and M. Krämer, 149-174. Berlin and New York: Mouton de Gruyter.

Rose, Sharon, and Rachel Walker. 2011. Harmony systems. In The Handbook of Phonological Theory, eds. J. Goldsmith, J. Riggle, and A. C. L. Yu, 240-290. Malden, MA: WileyBlackwell.

Sluyters, Willebrord. 1988. Vowel harmony, rule formats and underspecification: The dialect of Francavilla-Fontana. In Features, segmental structure and harmony processes, eds. H. van der Hulst and N. Smith, Vol. II, 161-184. Dordrecht: Foris.

Staubs, Robert, Michael Becker, Christopher Potts, Patrick Pratt, John J. McCarthy, and Joe Pater. 2010. OT-Help 2.0. Software package. Amherst, MA: University of Massachusetts Amherst.

Vago, Robert. 1973. Abstract vowel harmony systems in Uralic and Altaic languages. Language 49 (3): 579-605.

van Oostendorp, Marc. 2008. Incomplete devoicing in formal phonology. Lingua 118 (9): 13621374 .

van Oostendorp, Marc. 2014. Representing variation: The view from phonological theory. Talk given at the Theoretical Issues in Contemporary Phonology: Reading Tobias Scheer, February 6-8, Paris.

Walker, Rachel. 2005. Weak triggers in vowel harmony. Natural Language $\& 3$ Linguistic Theory 23 (4): 917-989.

Walker, Rachel. 2011. Vowel patterns in language. Cambridge University Press.

Wolf, Matthew. 2005. An autosegmental theory of quirky mutations. In Proceedings of the 24th West Coast Conference on Formal Linguistics, 370-378.

Youssef, Islam. 2013. Place assimilation in Arabic: contrasts, features and constraints. PhD diss, University of Troms $\varnothing$. 